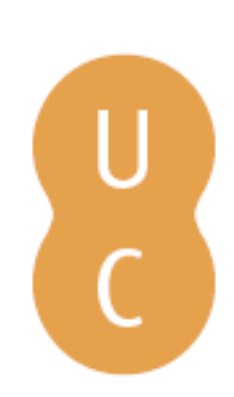

\title{
pompalina
}

\section{Characteristics of contrasting skeletal maturity status at the beginning of long-term soccer training}

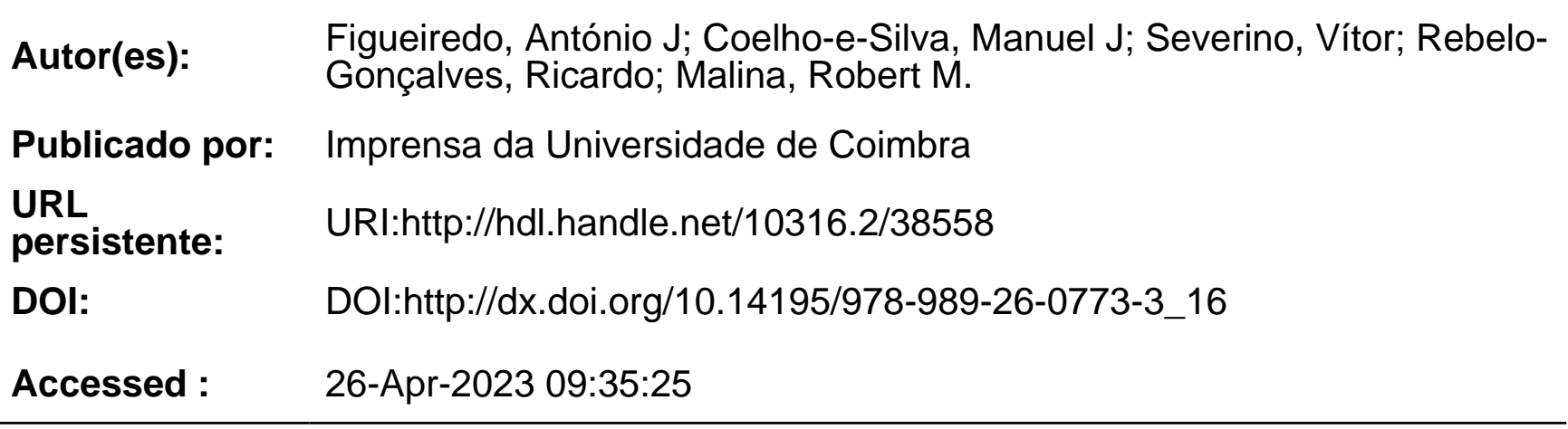

A navegação consulta e descarregamento dos títulos inseridos nas Bibliotecas Digitais UC Digitalis, UC Pombalina e UC Impactum, pressupõem a aceitação plena e sem reservas dos Termos e Condições de Uso destas Bibliotecas Digitais, disponíveis em https://digitalis.uc.pt/pt-pt/termos.

Conforme exposto nos referidos Termos e Condições de Uso, o descarregamento de títulos de acesso restrito requer uma licença válida de autorização devendo o utilizador aceder ao(s) documento(s) a partir de um endereço de IP da instituição detentora da supramencionada licença.

Ao utilizador é apenas permitido o descarregamento para uso pessoal, pelo que o emprego do(s) título(s) descarregado(s) para outro fim, designadamente comercial, carece de autorização do respetivo autor ou editor da obra.

Na medida em que todas as obras da UC Digitalis se encontram protegidas pelo Código do Direito de Autor e Direitos Conexos e demais legislação aplicável, toda a cópia, parcial ou total, deste documento, nos casos em que é legalmente admitida, deverá conter ou fazer-se acompanhar por este aviso.

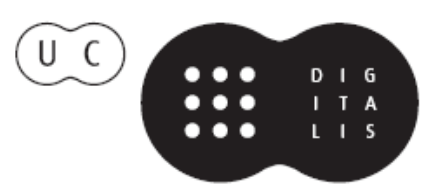




\section{GROWTH AND \\ MATURATION \\ IN HUMAN BIOLOGY \\ AND SPORTS}

FESTSCHRIFT HONORING ROBERT M. MALINA

BY FELLOWS AND COLLEAGUES

PETER TODD KATZMARZYK MANUEL J COELHO E SILVA

EDITORS 


\title{
CHARACTERISTICS OF CONTRASTING SKELETAL MATURITY STATUS AT THE BEGINNING OF LONG-TERM SOCCER TRAINING
}

\author{
António J Figueiredo \\ Manuel J Coelho-e-Silva \\ Vítor Severino \\ Ricardo Rebelo-Gonçalves \\ Robert M. Malina
}

(a) This chapter substantially overlaps a previously published manuscript (Figueiredo et al., 2009, in references). It is reproduced with permission: License number, 3157590204287; Content publisher: Informa Healthcare; Content publication: Annals of Human Biology).

\section{INTRODUCTION}

Participation in youth team sports is based primarily on chronological age groups which often span two years. Variation in size, function and skill associated with age per se and with maturity status within two-year age groups can be considerable. Studies of young athletes are often limited to growth and maturity status independent of functional capacities and sport-specific skills; the same is true of studies of function and skill (Malina 1994, Malina, Bouchard \& Bar-Or 2004). As a result, potential interactions among size, maturity, function and skill are often overlooked as youth progress in a sport.

Behavioral dimensions such as goal orientation, motivation, and perceptions of ability and success, have not ordinarily been considered in studies of young athletes that focus on biological and performance characteristics. Interactions between biological and behavioral variables may influence sport performance per se and persistence in a sport, and thus merit consideration. Observations of boys in the Adolescent Growth Study of the University of California (Berkeley), for example, indicated variation in behavioral characteristics associated with biological (skeletal age) maturity status (Jones 1949, 1958, 1965, Jones \& Bayley 1950, Eichorn 1963). Early maturing boys received greater social recognition from peers, were more at ease in social interactions, were considered more physically attractive and physically efficient, and were treated more favorably by adults compared to late maturing boys. On the other hand, late maturing boys were generally considered more eager, expressive and more attention seeking but lower in social prestige than early maturing boys. Although dated, the results highlight the potential relevance of interactions between biological maturity and behaviors among adolescent boys which are implicit in commonly used models of adaptations to puberty (Petersen \& 
Taylor 1980, Lerner 1985). The identification and quantification of potentially relevant behavioral variables may thus be of interest.

Achievement or goal orientation (Nicholls 1984) is a potentially relevant behavioral variable for success in sport. A task-oriented individual views his performance in terms of self-improvement, learning and effort, while an ego-oriented individual views his performance or ability relative to others (Duda 1995, McArdle \& Duda 2002). It is generally assumed that a task orientation is more adaptive than an ego orientation specifically from a motivational perspective. This in turn may influence continuation or discontinuation of participation in a sport. A comprehensive evaluation of correlates of goal orientation for physical activity, including sport, however, did not include any biological markers (Biddle, Wang, Kavussanu \& Spray 2003).

Given performance advantages associated with early maturation in boys, specifically size, strength, power and speed (Malina et al. 2004), it may be reasonable to assume that advanced maturation is associated with increased ego orientation. Evidence suggests that ego-oriented athletes tend to view ability as a stable concept and are more likely to attribute success to natural ability (Sarrazin, Biddle, Famose, Cury, Fox \& Durand 1996). The performance advantages associated with advanced maturity among adolescent boys might be perceived by them as natural ability. They may also be identified as having superior ability by coaches and peers. This in turn may contribute to higher levels of ego orientation. On the other hand, performance limitations of late maturing boys associated with small body size and less muscular strength compared to early maturing peers of the same age may contribute to task orientation, specifically focus on practice and training to improve ability and in turn mastery (Dweck \& Leggett 1988).

The purpose of this study is to compare the growth and maturity status, functional capacities, sport-specific skills and goal orientation of youth soccer players aged I $1-12$ years. Variation in body size, function, sport-specific skill and goal orientation of youth soccer players associated with differences in biological maturity status is specifically compared.

\section{METHODS}

\section{Sample}

The sample included 87 male soccer players 11.0 to 12.9 years from five clubs in the midlands of Portugal. All players were born in 1989 through 1992. The organization of youth soccer in Portugal uses two year age groups. Accordingly, players born in 1991 and 1992 were classified as infantiles (1 1.0-12.9 years). Players were from local clubs. Infantiles had a median of 3 years experience in the sport with a range from 1 to 5 years, while initiates had a median of 3 years of experience with a range of 2 to 6 years. Teams participated in a 9-month competitive season (September/May) through the Portuguese Soccer Federation. Players participated in three training sessions per week (each about 
90 minutes) and one game per week, usually on Saturday. The study was approved by the Scientific Committee of the University of Coimbra and each club. Athletes and their parents provided informed consent. Subjects were also informed that participation was voluntary and that they could withdraw from the study at any time.

\section{Protocol}

All data were collected within a two week period under standard conditions in an indoor facility at the University of Coimbra. Chronological (decimal) age was calculated as the difference between date of birth and date of the hand-wrist radiograph for the assessment of skeletal maturity (see below).

\section{Anthropometry}

Weight, height, sitting height and four skinfolds (triceps, subscapular, suprailiac, medial calf) were measured by a single trained observer following the protocol described in Lohman, Roche \& Martorell (1988). Players wore shorts and a t-shirt and shoes were removed. Leg (subischial) length was estimated as height minus sitting height. The sitting height/standing height ratio was calculated. The skinfolds were summed to provide an estimate of overall subcutaneous adiposity.

\section{$\underline{\text { Functional Capacities }}$}

Aerobic and anaerobic function, agility and muscular power were tested. The yo-yo intermittent endurance test - level I (Bangsbo 1994; see also Reilly 200 I; Reilly \& Doran 2003; Balson 1994) was used as the measure of aerobic performance. Level I of the yoyo intermittent endurance test requires the subject to perform a series of 20-meter shuttle runs following a cadence set by an audio metronome with a 5-second rest interval between every 40 meters. Speed is increased at intervals, i.e., the time between the signals is shortened. The objective of the test is to perform as many shuttles as possible and the score corresponds to the total amount of meters covered until the athlete is no longer able to maintain the required speed, e.g., if a subject completed 40 shuttles, his score was 1600 meters $(40 \times 2 \times 20)$. The relationship between the yo-yo intermittent endurance test and the PACER (progressive aerobic cardiovascular endurance run test, Léger, Mercier, Gadoury \& Lambert 1988) was examined in 69 male soccer players 13-18 years (Figueiredo, Coelho e Silva \& Malina 2004). The correlation between tests was 0.78 $(\mathrm{p} \leq .0 \mathrm{l})$ and the shared variance between the intermittent and continuous tests was $61 \%$. In a study of adult soccer players ( $n=81,23.5 \pm 4.0$ years) at three competitive levels (low, high [amateur] and professional) the intermittent test had higher predictive value in discriminating players by competitive level (Lemmink, Verheijen \& Visscher 2004).

Anaerobic fitness was assessed with the 7-sprint protocol (Bangsbo 1994, see also Reilly 200I, Reilly \& Doran 2003). The test includes 7 consecutive sprints (about 35 $\mathrm{m}$ with a slalom) with a recovery period of 25 seconds between sprints during which the 
subject runs/walks from the end line back to the starting line. The time for each sprint was recorded by a digital chronometer connected to photoelectric cells (Globus Ergo Tester Pro). The protocol provides for the following indicators: the faster sprint from the first two trials (measure of speed), the slower sprint from the last two trials, and the mean of all sprints. Prior to the study, the relationship between the 7-sprint test and the Wingate test was examined in 29 male soccer players $15.7 \pm 0.7$ years (Figueiredo, Coelho e Silva \& Malina 2003). The first and the third sprints had the highest correlation with relative anaerobic peak power. The outcomes of the 7-sprints were more correlated with anaerobic peak than with anaerobic mean power. Correlations were also of higher magnitude when anaerobic peak power was expressed as watts per kilogram of body weight. Note, however, that the correlation between the fastest sprint and relative anaerobic peak power was moderate $(r=0.44, p \leq 0.01)$, suggesting that anaerobic outcomes were not independent of test modality (cycling $\times$ running).

Agility was assessed with the 10x5-meter shuttle. The test includes running speed and ability to change directions rapidly. Two trials were performed and the better of the two was retained for analysis.

Explosive power was assessed with the vertical jump using the ergo-jump protocol which includes two components: squat jump and counter-movement jump (Bosco 1994). Two trials were administered for each test and the better trial was retained for analysis.

\section{Soccer Skills}

Four tests of soccer skill were administered: ball control with the body, dribbling speed, shooting accuracy and the wall pass. The test battery was selected on the basis of a principal component analysis of eight tests of soccer skills, six from the Portuguese Soccer Federation - ball control with the body, ball control with the head, dribbling speed, dribbling with a pass, passing accuracy, and shooting accuracy (Federação Portuguesa de Futebol 1986) and two others, a wall pass and slalom dribble test (Kirkendall, Gruber \& Johnson 1987), administered to 39 youth players (Coelho e Silva, Figueiredo \& Malina 2004). Results of the principal components analysis indicated two factors which accounted for $57 \%$ of the variance. Seven of the eight tests loaded on the first factor (40\% of the variance) while the test of shooting accuracy loaded very high on the second factor (17\% of the variance). The slalom dribble and the test of passing accuracy loaded on the two extracted factors and were thus excluded from the test battery. The test of ball control with the body had higher communality than the test of ball control with the head and was thus retained. The wall pass had higher communality than dribbling with a pass and was retained in the test battery. Thus, the final battery included four tests of soccer skill: ball control with the body, dribbling speed, shooting accuracy and wall pass. 


\section{Maturity Status}

Posterior-anterior radiographs of the left hand-wrist were taken. The Fels method (Roche, Chumlea \& Thissen 1988) was used to estimate skeletal age (SA). The Fels method utilizes specific criteria for each bone of the hand-wrist and ratios of linear measurements of epiphyseal and metaphyseal widths. Ratings are entered into a program (Felshw 1.0 Software) to calculate SA and its standard error of estimate. All radiographs were assessed by a single observer. In addition to SA, stage of pubic hair was assessed at clinical examination by a trained physician. Stages as described by Tanner (1962) were used.

\section{Goal Orientation}

A Portuguese version (Fonseca and Biddle 1996) of the Task and Ego Orientation in Sport Questionnaire (TEOSQ, Duda 1989, Chi \& Duda 1992) was completed by all players. The TEOSQ includes 13 items which are rated on a 5 point Likert scale ranging from strongly disagree ( 1 ), disagree, neutral, agree and strongly agree (5). Seven items reflect a task orientation while 6 reflect an ego orientation. Examples of a task focus are: "I learn a new skill and it makes me want to practice more" and "I learn something that is fun to do," while examples of an ego focus are: "I'm the only one who can do the play or the skill" and "I can do better than my friends." Cronbach's alphas (task, 0.76; ego, 0.85) indicate acceptable internal consistency. Confirmatory factor analysis using an independent sample indicated acceptable fit of the data (CFI $=0.91, \mathrm{GFI}=0.93, \mathrm{SRMR}=$ 0.07).

\section{Quality Control}

A sample of 32 players was measured and tested on a second occasion within one week. Intra-observer technical errors of measurement for anthropometric dimensions and coefficients of reliability for the functional capacity and soccer skill tests were calculated. The technical error of measurement is the square root of the squared differences of replicates divided by twice the number of pairs:

$$
\sigma_{\mathrm{e}}=\sqrt{ } \sum \mathrm{d}^{2} / 2 \mathrm{~N} \text { (Malina, Hamill \& Lemeshow 1973). }
$$

It is also known as the measurement error standard deviation. The coefficient of reliability is based on the ratio of within-subject $(r)$ and inter-subject ( $s$ ) variances:

$$
R=1-\left(r^{2} / s^{2}\right) \text { (Mueller \& Martorell 1988). }
$$

Higher values indicate greater reliability. Technical errors and reliability coefficients for the present study are summarized in 
Table I. Intra-observer technical errors of measurement $\left(\sigma_{e}\right)$ for anthropometric dimensions and reliability coefficients (R) for functional capacity and soccer skill tests.

\begin{tabular}{llll}
\hline Anthropometry & $\sigma_{\mathrm{e}}$ & Functional Capacity and Skill & $\mathrm{R}$ \\
\hline Weight, $\mathrm{kg}$ & & & \\
Height, $\mathrm{cm}$ & 0.47 & Squat jump & 0.83 \\
Sitting height, cm & 0.27 & Counter-movement jump & 0.87 \\
Skinfolds, mm & 0.31 & Agility shuttle run & 0.84 \\
Skinfold triceps & & Intermittent endurance run & 0.88 \\
Skinfold subscapular & 0.52 & Best sprint & 0.81 \\
Skinfold suprailiac & 0.53 & Mean sprint & 0.88 \\
Skinfold medial calf & 0.72 & Ball control & 0.77 \\
& 0.47 & Dribbling speed & 0.74 \\
& & Wall pass & 0.83 \\
& & Shooting accuracy & 0.71
\end{tabular}

Technical errors for anthropometric dimensions compare favorably with corresponding intra- and inter-observer errors in several health surveys in the United States and a variety of field surveys, including studies of young athletes (Malina 1995), while reliability coefficients indicate moderate to high reliabilities which are adequate for group comparisons.

\section{Maturity Classification}

The difference between SA and CA (SA minus CA) provides an estimate of relative skeletal age (RSA). The difference between SA and CA was used to classify players as follows:

Late (delayed), SA younger than CA by $>1.0 \mathrm{yr}$

Average (on time), $\mathrm{SA} \pm 1.0$ yr CA

Early (advanced), SA older than CA by $>1.0 \mathrm{yr}$

Mature, skeletally mature.

The classification criteria are similar to previous studies that used the difference between SA and CA to classify youth athletes in several sports into contrasting maturity categories (Krogman 1959, Rochelle, Kelliher \& Thornton 1961, Peña Reyes, Cardenas-Barahona \& Malina 1994, Malina, Peña Reyes, Eisenmann, Horta, Rodrigues \& Miller 2000, Malina, 
Dompier, Powell, Barron \& Moore 2007, Malina, Chamorro, Serratosa \& Morate 2007, Malina et al. 2004). The band of \pm 1.0 year approximates standard deviations for SA within half-year CA groups in the Fels sample of boys 12 through 16 years, 0.94 to 1.26 years (Roche et al. 1988). Using a band of one year also allows for the error associated with the assessment of SA and provides a broad range of youth who are classified as on time in maturity status. A narrow range, e.g., a band of \pm 3 months to define early and late maturity (e.g., Kemper, Verschuur \& Ritmeester 1986), is well within the range of the error of SA assessment. The median standard error of estimate for SA assessments of the total sample $(n=159)$ was 0.30 year with a range from 0.27 to 0.42 year.

\section{Analysis}

Descriptive statistics were calculated by competitive age group for all variables except stage of PH; for the latter, the distribution of stages was noted. ANOVA was used to compare CA, body size and proportions, functional capacities, soccer skills and goal orientation by competitive age group and among late, average (on time) and early maturing players. An alpha level of 5\% was accepted. Effect size was estimated with partial eta squared $\left(\eta^{2}\right)$. If a comparison was significant among maturity groups, pairwise comparisons with a Bonferroni adjustment were used to identify which groups differed.

\section{RESULTS}

Skeletal age approximates chronological in $11-12$ year old players. Pubic hair stages I through 3 are represented among $1 \mid-12$ year old players with the majority in $\mathrm{PHI}(\mathrm{n}=47$, $54 \%)$, about one-third in $\mathrm{PH} 2(\mathrm{n}=30,34 \%)$ and few in $\mathrm{PH} 3(\mathrm{n}=10,11 \%)$. The classification of players by skeletal maturity status is summarized in Table 2: 17 are late (20\%), 45 are on time (52\%) and 25 are early (29\%) in skeletal maturation. Distributions of stages of pubic hair development are also summarized by skeletal maturity classification in Table 2: I5 of 17 late maturing players are in $\mathrm{PHI}$ (88\%); 4 I of 45 players classified as on time are in $\mathrm{PHI}$ (53\%) and $\mathrm{PH} 2$ (38\%); while stages $\mathrm{PHI}$ (32\%), $\mathrm{PH} 2$ (44\%) and $\mathrm{PH} 3$ (24\%) are represented in players classified as early maturing.

Table 2. Distribution of players by maturity status (SA minus CA) and distribution of stages of pubic hair by skeletal maturity status.

\begin{tabular}{lrrr}
\hline & $\begin{array}{c}\text { Late } \\
(n=17)\end{array}$ & $\begin{array}{c}\text { On Time } \\
(n=45)\end{array}$ & $\begin{array}{c}\text { Early } \\
(n=25)\end{array}$ \\
\hline $\mathrm{PH} \mathrm{1}$ & 15 & 24 & 8 \\
$\mathrm{PH} \mathrm{2}$ & 2 & 17 & 11 \\
$\mathrm{PH} 3$ & 0 & 4 & 6 \\
\hline
\end{tabular}


Characteristics of players of contrasting maturity status are summarized in Table 3. Skeletal age is included in the tables to illustrate the maturity contrasts of the groups. Chronological ages of players of contrasting skeletal maturity status do not differ, but early maturing boys are significantly heavier and taller with longer segment lengths than average (on time) and late maturing boys. The gradient is early $>$ on time $>$ late maturing. The gradient is significant for subcutaneous adiposity. The sitting height ratio does not differ among maturity groups.

Table 3. Age, body size, functional capacities, sport-specific skills and goal orientation of II12 year old players classified as late, on time and early in skeletal maturation and results of ANOVAs and estimated effect size $\left(\eta^{2}\right)$.

\begin{tabular}{lllllll}
\hline & $\begin{array}{l}\text { Late } \\
(\mathrm{n}=17)\end{array}$ & $\begin{array}{l}\text { On time } \\
(\mathrm{n}=45)\end{array}$ & $\begin{array}{l}\text { Early } \\
(\mathrm{n}=25)\end{array}$ & $\mathrm{F}$ & $\mathrm{P}$ & $\eta^{2}$ \\
\hline Chronological age (CA), yrs & $11.9 \pm 0.6$ & $11.8 \pm 0.5$ & $11.7 \pm 0.6$ & 0.63 & & 0.15 \\
Skeletal age (SA), yrs & $10.1 \pm 0.8$ & $11.8 \pm 0.8$ & $13.6 \pm 0.6$ & & & \\
Weight, kg & $33.6 \pm 3.6$ & $37.5 \pm 5.1$ & $42.1 \pm 7.1$ & 12.55 & $<0.01$ & 0.23 \\
Height, cm & $139.4 \pm 4 / 5$ & $144.6 \pm 5.9$ & $148.4 \pm 7.3$ & 11.12 & $<0.01$ & 0.21 \\
Sitting height, cm & $70.6 \pm 2.5$ & $72.7 \pm 2.7$ & $75.0 \pm 2.7$ & 14.12 & $<0.01$ & 0.25 \\
Estimated leg length, cm & $68.7 \pm 3.5$ & $71.9 \pm 3.9$ & $73.3 \pm 5.2$ & 6.09 & $<0.01$ & 0.13 \\
Sitting height ratio, \% & $50.7 \pm 1.5$ & $50.3 \pm 1.1$ & $50.6 \pm 1.4$ & 0.86 & & 0.02 \\
Sum of skinfolds, mm & $23.2 \pm 7.0$ & $32.4 \pm 12.3$ & $38.5 \pm 18.5$ & 6.33 & $<0.01$ & 0.13 \\
Fastest sprint, sec & $8.28 \pm 0.43$ & $8.38 \pm 0.52$ & $8.41 \pm 0.52$ & 0.37 & & 0.10 \\
Mean sprint, sec & $8.63 \pm 0.46$ & $8.82 \pm 0.63$ & $8.85 \pm 0.63$ & 0.75 & & 0.02 \\
Agility shuttle run, sec & $20.24 \pm 1.23$ & $20.61 \pm 1.29$ & $20.67 \pm 1.45$ & 0.60 & & 0.01 \\
Endurance run, m & $1774 \pm 725$ & $1308 \pm 657$ & $1208 \pm 788$ & 3.57 & $<0.05$ & 0.08 \\
Squat jump, cm & $23.3 \pm 6.3$ & $24.7 \pm 5.1$ & $24.9 \pm 5.6$ & 0.92 & & 0.02 \\
Counter-mov. jump, cm & $22.7 \pm 5.4$ & $25.8 \pm 5.5$ & $26.3 \pm 5.2$ & 1.22 & & 0.03 \\
Ball control, \# hits & $23.6 \pm 21.1$ & $26.3 \pm 25.7$ & $19.6 \pm 14.6$ & 0.75 & & 0.02 \\
Dribbling speed, sec & $15.56 \pm 1.51$ & $15.76 \pm 1.93$ & $15.93 \pm 1.82$ & 0.21 & & 0.01 \\
Wall pass, points & $19.2 \pm 2.1$ & $17.5 \pm 3.1$ & $17.5 \pm 3.1$ & 1.59 & & 0.04 \\
Shooting accuracy, points & $6.9 \pm 2.1$ & $6.8 \pm 2.4$ & $6.8 \pm 2.4$ & 0.47 & & 0.01 \\
Task orientation & $4.4 \pm 0.4$ & $4.3 \pm 0.5$ & $4.3 \pm 0.4$ & 0.25 & & 0.01 \\
Ego orientation & $2.1 \pm 0.6$ & $2.1 \pm 0.7$ & $2.0 \pm 0.7$ & 0.00 & & 0.00 \\
& & & & & & \\
\hline
\end{tabular}

Functional capacities and soccer-specific skills, with few exceptions, do not differ among boys of contrasting maturity status within each age group. Only aerobic endurance differs among maturity groups. Late maturing boys have greater endurance capacity than on time and early maturing boys who do not differ (Table 3). The difference persists when height and weight are statistically controlled with ANCOVA (not shown). Task and ego goal orientations also do not differ among players of contrasting maturity status and no gradient in means across maturity groups is suggested. 


\section{DISCUSSION}

Variation in body size associated with contrasting maturity status in youth soccer players was similar to that for adolescent males in general among whom boys advanced in skeletal maturity are taller and heavier than those on time and late in skeletal maturity (Malina et al. 2004). On the other hand, soccer players who vary in maturity status did not differ consistently in functional capacities and soccer-specific skills, which contrasts observations of adolescent males in general among whom there is a maturity gradient of early $>$ on time $>$ late in tests of strength, speed, power and agility (Jones 1949, Lefevre, Beunen, Simons, Renson, Ostyn \& Van Gerven 1988, Lefevre, Beunen, Steens, Claessens \& Renson 1990). The differences among boys of contrasting maturity status also tend to persist when maturity-related variation in height and weight are statistically controlled (Beunen, Ostyn, Simons, Renson \& Van Gerven 198I). Performance differences among maturity groups are apparent by 13 years of age and tend to be greatest at 14 and 15 years (Jones 1949, Lefevre et al. 1988, 1990, Malina et al. 2004). The lack of consistent differences in functional capacities and skills among soccer players of contrasting maturity status thus contrasts that noted in adolescent boys in general. The lack of functional and skill differences among adolescent soccer players likely reflects selective practices and/or positive influences of regular fitness and skill training associated with the sport. A related factor for which data are not currently available may selective drop out or persistence in the sport.

In contrast to other functional capacities tested, later maturing $11-12$ year old soccer players performed significantly better on the endurance shuttle run. Comparative data for the yo-yo intermittent shuttle run test of aerobic endurance in boys of contrasting maturity status are not available. Among Polish boys I |- | 4 years enrolled in a sports school, absolute peak oxygen uptake (L/min) differed significantly among early, on time and late maturing boys, while relative peak oxygen uptake $(\mathrm{ml} / \mathrm{kg} / \mathrm{min})$ did not (Malina, Beunen, Lefevre \& Woynarowska 1997). Absolute peak oxygen uptake was lower in later maturing boys across all ages. Although the overall comparison was not significant, relative peak oxygen uptake was higher, on average, in late maturing compared to on time and early maturing boys I I through 13 years, but the difference among maturity groups was negligible among 14 year old boys of contrasting maturity status (Malina et al. 1997). The results suggest an important role for lower body mass in endurance performance of adolescent boys, including soccer players. Among adolescent male athletes, including a subsample of soccer players, pubertal status had an effect on aerobic power in addition to that of age and body size (Baxter-Jones, Goldstein \& Helms 1993). 
Among players 11-12 years (early adolescence), athletes spanning the skeletal maturity spectrum from late (delayed) to early (advanced) were represented. The height, weight and maturity of boys in the present study were consistent with other observations for youth soccer players (Malina 1994, 2003), and also with the hypothesis that late maturing boys are excluded from soccer either voluntarily as in dropping out or systematically as in cutting and/or early maturing boys are preferentially selected as age and sport specialization increase (Malina 2003). The trends were also consistent for estimates of skeletal maturity based on both the Fels (Roche et al. 1988) and TannerWhitehouse (Tanner, Whitehouse, Cameron, Marshall, Healy \& Goldstein 1983) methods in Mexican (Peña et al. 1994), Portuguese (Malina et al. 2000) and Spanish (Malina, Chamorro, Serratosa \& Morate 2007) youth players.

Stages of pubic hair were consistent with skeletal maturity of the youth soccer players, although there was more variation in the former. The variation is due, in part, to method as the scales for pubic hair and skeletal age differ. Further, stage of pubic hair indicates pubertal status at the time of examination and does not provide information on when a player entered the stage or how long he has been in the stage (Malina et al. 2004). Among players II-I2 years, stages PHI through PH3 were represented (Table 3), but most $(88 \%)$ late maturing boys were prepubertal $(\mathrm{PHI})$.

The present study is limited to youth soccer players in Portugal and a question of potential interest is the growth and maturity status of the players relative to the general population of Portuguese youth. The younger age group of soccer players tended to be, on average, slightly shorter and lighter than Portuguese boys of the same age from Madeira (Freitas et al. 2002) and the Azores (Maia \& Lopes 2007). In contrast, the older players tended to be, on average, similar in height and weight to boys from Madeira; they were also similar in height to boys from the Azores but were lighter in weight. The comparisons of body weight need to be tempered; youth soccer players in each age group had, on average, consistently thinner skinfold thicknesses than boys from Madeira and the Azores which would suggest proportionally more lean mass. It was not possible to compare the skeletal maturity status of the youth soccer players with the general population as data utilizing the Fels method are not presently available. Of relevance, Portuguese boys from Madeira tended to be advanced, on average, in skeletal maturity (Tanner-Whitehouse 2, radius-ulna-short bone scores) compared to age-matched boys from Belgium (Freitas et al. 2004).

Players did not differ in task orientation, but older players had a significantly lower ego orientation than younger players (Table 2). This may reflect increased emphasis on individual and team improvement associated with experience in the sport. In an independent sample of club soccer players 13-16 years of age $(n=40)$ in Portugal (Gonçalves, Freitas, Cardoso, Lourenço, Coelho e Silva, Lee \& Chiatzirantis 2005), task orientation (4.23 \pm 0.74$)$ was similar while ego orientation was considerably higher $(2.80 \pm 0.9 \mathrm{I})$ than in the present study. Corresponding data for an older sample elite Dutch youth soccer players ( $16.4 \pm 2.0$ years) indicated, on average, a slightly lower task 


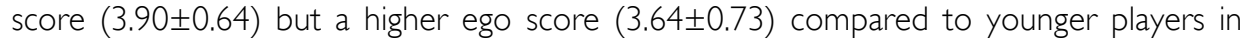
the present study (Van-Yperen \& Duda 1999). In the Dutch sample, improvement in skilled performance during a season, as assessed by coaches, was associated with higher task orientation. On the other hand, an ego orientation, described as "a dysfunctional motivational pattern," was associated with negative peer acceptance among Norwegian youth soccer players 12-19 years of age (Ommundsen, Roberts, Lemyre \& Miller 2005). Although this study utilized a different scale for the assessment of task and ego orientation compared to that used in the present study, the results suggest than goal orientation may influence peer relationships among adolescent male soccer players.

In the present study, youth soccer players of contrasting maturity status did not differ in task or ego orientation. This contrasted expectations that advanced maturation would be associated with increased ego orientation and late maturation would be associated with increased task orientation. Ego-oriented athletes are more likely to attribute success to natural ability (Sarrazin et al. 1996) and performance advantages associated with advanced maturity (Malina et al. 2004) might be perceived by adolescent boys as natural ability. Success in sport at early adolescent ages, which may be due in part to maturity mismatches, may lead to boys advanced in maturity status to be labeled as having superior ability by coaches and peers. These factors may in turn contribute to higher ego orientation in early maturing athletes. On the other hand, performance limitations of late maturing boys associated with small body size and less muscular strength and power compared to early maturing peers may lead them to focus on practice and training to improve ability and mastery of sport skills and in turn higher task orientation. Models of adaptations to puberty include the underlying biological changes and their overt manifestations. Petersen \& Taylor (1980), for example, offered a model that focuses on exogenous and endogenous factors that may mediate between biological changes during puberty and psychological outcomes. Lerner (1985), on the other hand, proposed a contextual model that emphasizes the "goodness of fit" between physical and psychological changes during puberty and the context within which they occur. Both models deal with adolescents in general, and have not been often applied to a sport context with its specific demands (Monsma and Malina 2004, Monsma, Malina and Feltz 2006). The models noted have their roots in developmental psychology but each has commonalities with the biocultural framework in studies of human variability and adaptation to the environment (Baker 1966, Lasker 1969). The biocultural approach applied to youth implies that biological growth and maturation do not proceed in isolation of the behavioral realm which is largely rooted in culture.

\section{REFERENCES}

Baker, P.T. (1966). Human biological variation as an adaptive response to the environment. Eugenics Quarterly 13, 81-91.

Balson, P. (1994). Evaluation of Physical Performance. In Football (soccer), edited by B. Ekblom (Oxford: Blackwell Science), pp. I02- 123. 
Bangsbo, J. (1994). Fitness Training in Football - A Scientific Approach (Bagsvaerd: HO and Storm).

Bosco, C. (1994). La valoration de la fuerza com el test de Bosco. In Coleccion Deporte y Entrenamiento, translated by J. Riu (Barcelona: Editorial Paidotribo).

Baxter-Jones, A., Goldstein, H., \& Helms, P. (1993). The development of aerobic power in young athletes. Journal of Applied Physiology, 75, I I60- I I 67.

Beunen, G., Ostyn, M., Simons, J., Renson, R., \& Van Gerven, D. (198I). Chronological and biological age as related to physical fitness in boys 12 to 19 years. Annals of Human Biology, 8, 321-331.

Chi, L., \& Duda, J. ( 1995). Multi-sample confirmatory factor analysis of the Task and Ego Orientation in Sport Questionnaire. Research Quarterly for Exercise and Sport, 66, 91-98.

Coelho e Silva, M., Figueiredo, A, \& Malina, R.M. (2004). Avaliação da mestria motora no inicio da preparação desportiva de jovens futebolistas. Horizonte - Revista de Educação Física e Desporto, 19 ( | | 4), 23-32.

Duda, J.L. (1989). Relationship between task and ego orientation and the perceived purpose of sport among high school athletes. Journal of Sports and Exercise Psychology, I I, 318-335.

Duda, J.L. (1992). Motivation in sport settings: A goal perspective approach. In Motivation in Sport and Exercise, edited by G.C. Roberts (Champaign, IL: Human Kinetics), pp. 57-91.

Dweck, C.S., \& Leggett, E.L. (1988). A social-cognitive approach to motivation and personality. Psychological Review, 95, 256-273.

Eichorn, D.H., 1963, Biological correlates of behavior. Yearbook of the National Association for the Study of Education, 62 (part I), 4-6I.

Federação Portuguesa de Futebol (1986). Habilidades e destrezas do futebol: Os skills do futebol (Lisboa: Editora Federação Portuguesa de Futebol).

Figueiredo, A., Coelho e Silva, M., \& Malina, R.M. (2003). Anaerobic performance in youth football: A laboratory test versus a field test. II Congresso Mundial de Ciencias dela Actividad Fisica y del Deporte. University of Granada, pp. 60-63.

Figueiredo, A., Coelho e Silva, M.J., \& Malina, R.M. (2004). Aerobic assessment of youth soccer players: Correlation between continuous and intermittent progressive maximal field tests. In Book of Abstracts, $9^{\text {th }}$ Annual Congress of the European College of Sport Science, edited by E. Van Praagh and J. Coudert (ClermondFerrand: Université Blaise Bascal, Université D'Auvergne), p. 294.

Fonseca, A.M., \& Biddle, S.J. (1996). Estudo inicial para a adaptação do Task and Ego Orientation in Sport Questionnaire (TEOSQ) à realidade portuguesa. [Exploratory study to adapt the Task and Ego Orientation in Sport Questionnaire (TEOSQ) to Portuguese reality.] Proceedings of the IV International Conference on Psychological Assessment: Development and Contexts (Braga, Minho University Press).

Freitas, D.L., Maia, J.A., Beunen, G.P., Lefevre, J.A., Claessens, A.L, Marques, A.T., Rodrigues, A.L., Silva, C.A., \& Crespo, M.T. (2002). Crescimento somatico, maturação biologica, aptidão fisica, actividade fisica e estatuto socioeconomico do crianças e 
adolescents Madeirensesi (Funchal, Portugal, Seccão Autonoma de Educação Fisica e Desporto, Universidade de Madeira).

Freitas, D., Maia, J., Beunen, G., Lefevre, J., Claessens, A., Marques, A., Rodrigues, A., Silva, C., Crespo, M., Thomis, M., Sousa, A., \& Malina, R.M. (2004). Skeletal maturity and socio-economic status in Portuguese children and youths: the Madeira Growth Study. Annals of Human Biology, 3 I , 408-420.

Gonçalves, C.E., Freitas, F., Cardoso, L., Lourenço, J., Coelho e Silva, M.J., Lee, M.J., \& Chiatzirantis, N. (2005). Valores, atitudes e orientação para a realização de objectivos no desporto de jovens. (Lisbon, National Institute of Sport).

Jones, H.E. (1949). Motor Performance and Growth (Berkeley: University of California Press).

Jones, M.C. (1958). A study of socializations patterns at the high school level. Journal of Genetic Psychology, 93, 87-1।1.

Jones, M.C. (1965). Psychological correlates of somatic development. Child Development, 36, 899-9II.

Jones, M.C., \& Bayley, N. (1950). Physical maturing among boys as related to behavior. Journal of Educational Psychology, 4I, 129- 148.

Kemper, H.C.G., Verschuur, R., and Ritmeester, J.W. (1986). Maximal aerobic power in early and late maturing teenagers. In Children and Exercise XII, edited by J. Rutenfranz, R. Mocellin, \& F. Klimt (Champaign, IL: Human Kinetics), pp. 21 3-225.

Kirkendall, D.T., Gruber, J., \& Johnson, R. (1987). Measurement and Evaluation in Physical Education, $2^{\text {nd }}$ edition (Champaign, IL: Human Kinetics).

Krogman, W.M. (1959). Maturation age of 55 boys in the Little League World Series, 1957. Research Quarterly, 30, 54-56.

Lasker, G.W. (1969). Human biological adaptability: The ecological approach in physical anthropology. Science, | 66, |480-| 486.

Lefevre, J., Beunen, G., Simons, J., Renson, R., Ostyn, M., \& Van Gerven, D. (1988). Motor performance as related to age at peak height velocity. Paper presented at the Fifth International Auxology Congress, Exeter University, Exeter, United Kingdom

Lefevre, J., Beunen, G., Steens, G., Claessens, A., \& Renson, R. (1990). Motor performance during adolescence and age thirty as related to age at peak height velocity. Annals of Human Biology, I 7, 423-435.

Leger, L., Mercier, D., Gadoury, C., \& Lambert, J. (1988). The multistage 20-meter shuttle run test for aerobic fitness. Journal of Sports Science, 6, 93- 100.

Lemmink, K., Verheijen, R., \& Visscher, C. (2004). The discriminative power of the interval shuttle run test and the maximal multistage shuttle run test for playing level of soccer. Journal of Sports Medicine and Physical Fitness, 44, 233-239.

Lerner R.M. (1985). Adolescent maturational changes and psycho-social development: A dynamic interactional perspective. Journal of Youth and Adolescence, I 4, 355-372.

Lohman, T.G., Roche, A.F., \& Martorell, R. (1988). Anthropometric Standardization Reference Manual (Champaign, IL: Human Kinetics).

Maia, J.A.R., \& Lopes, V.P. (2007). Crescimento e desenvolvimento de crianças e jovens Açorianos (Porto, Faculdade de Desporto da Universidade de Porto). 
Malina, R.M. (1994). Physical growth and biological maturation of young athletes. Exercise and Sport Sciences Reviews, 22, 389-433.

Malina, R.M. (1995). Anthropometry. In Physiological Assessment of Human Fitness, edited by P.J. Maud and C. Foster (Champaign, IL: Human Kinetics), pp. 205-219.

Malina, R.M. (2003). Growth and maturity status of young soccer (football) players. In Science and Socer, $2^{\text {nd }}$ edition, edited by T. Reilly and A.M. Williams M (London: Routledge), pp 287-306.

Malina, R.M., Beunen, G., Lefevre, J., \& Woynarowska, B. (1997). Maturity-associated variation in peak oxygen uptake in active adolescent boys and girls. Annals of Human Biology, 24, 19-31.

Malina, R.M., Bouchard, C., \& Bar-Or, O. (2004). Growth, Maturation, and Physical Activity, $2^{\text {nd }}$ edition (Champaign, IL: Human Kinetics).

Malina, R.M., Chamorro, M., Serratosa, L., \& Morate, F. (2007). TW3 and Fels skeletal ages in elite youth soccer players. Annals of Human Biology, 34, 265-272.

Malina, R.M., Dompier, T.P., Powell, J.W., Barron, M.J., \& Moore, M.T. (2007). Validation of a noninvasive maturity estimate relative to skeletal age in youth football players. Clinical Journal of Sports Medicine, 17, 362-368.

Malina, R.M., Hamill, P.V.V., \& Lemeshow, S. (1973). Selected measurements of children 6II years, United States. Vital and Health Statistics, Series II, No. I23 (Washington, DC: Department of Health and Human Services, U.S. Government Printing Office).

Malina, R.M., Peña Reyes, M.E., Eisenmann, J.C., Horta, L., Rodrigues, J., \& Miller, R. (2000). Height, mass, and skeletal maturity of elite Portuguese soccer players I I-16 years of age. Journal of Sports Sciences, 1 8, 685-693.

McArdle, S., \& Duda, J.L. (2002). Implications of the motivational climate in youth sports. In Children and Youth in Sport, $2^{\text {nd }}$ edition, edited by F.L. Smoll and R.E. Smith (Dubuque, IA: Kendall/Hunt Publishing Company), pp. 409-434.

Monsma, E.V., \& Malina, R.M. (2004). Correlates of eating disorders risk among female figure skaters: A profile of adolescent competitors. Psychology of Sport and Exercise, 5, 447-460.

Monsma, E.V., Malina, R.M., \& Feltz, D.L. (2006). Puberty and physical self-perceptions of competitive female figure skaters: An interdisciplinary approach. Research Quarterly for Exercise and Sport, 77, I58- 166.

Mueller, W.H., \& Martorell, R. (1988). Reliability and accuracy of measurement. In Anthropometric Standardization Reference Manual, edited by T.G. Lohman, A.F. Roche and R. Martorell (Champaign, IL: Human Kinetics), pp. 83-86.

Nicholls, J. (1984). Achievement motivation: Conception of ability, subjective experience, task choice, and performance. Psychological Review, 91, 328-346.

Ommundsen, Y., Roberts, G.C., Lemyre, P.N., \& Miller, B.W. (2005). Peer relationships in adolescent competitive soccer: Associations to perceived motivational climate, achievement goals and perfectionism. Journal of Sports Sciences, 23, 977-989.

Peña Reyes, M.E., Cardenas-Barahona, E., \& Malina, R.M. (1994). Growth, physique, and skeletal maturation of soccer players 7-17 years of age. Humanbiologia Budapestinensis, 5, 453-458. 
Petersen, A., \& Taylor, B. (1980). The biological approach to adolescence. In Handbook of Adolescent Psychology, edited by J. Adelson (New York: Wiley), pp. II7-I55.

Reilly, T. (200I). Assessment of performance in team games. In Kinanthropometry and Exercise Physiology Laboratory Manual: Tests, Procedures and Data, $2^{\text {nd }}$ edition, edited by R.G. Eston and T. Reilly (London. Routledge), pp. 171-182.

Reilly, T., \& Doran, D. (2003). Fitness assessment. In Science and Soccer, $2^{\text {nd }}$ edition, edited by T. Reilly and A.M. Williams (London: Routledge), pp. 21-46.

Rochelle, R.H., Kelliher, M.S., \& Thornton, R. (196|). Relationship of maturation age to incidence of injury in tackle football. Research Quarterly, 32, 78-82.

Sarrazin, P., Biddle, S., Famose, J.P., Cury, F., Fox, K., \& Duranc, M. (1996). Goal orientations and conceptions of the nature of sport ability in children: A social cognitive approach. British Journal of Social Psychology, 35, 399-4I4.

Tanner, J.M. (1962). Growth at Adolescence, $2^{\text {nd }}$ edition (Oxford: Blackwell).

Van-Yperen, N.W., \& Duda, J.L., 1999. Goal orientations, beliefs about success, and performance improvement among young elite Dutch soccer players. Scandinavian Journal of Medicine and Science in Sports, 9, 358-364. 